\title{
GENETIC IMPLICATIONS IN VITILIGO AND VITILIGO-ASSOCIATED DISEASES
}

\section{Ana Maria A. STANESCU1 ${ }^{1}$, loana V. GRAJDEANU ${ }^{1}$, Bogdan SERBAN ${ }^{1,2}$, Ovidiu G. BRATU ${ }^{1,3}$, Bogdan SOCEA ${ }^{1,4}$, Anca PANTEA STOIAN ${ }^{1}$, Camelia C. DIACONU ${ }^{1,5}$}

${ }^{1}$ University of Medicine and Pharmacy „Carol Davila“, Bucharest, Romania

2 Emergency University Hospital Bucharest, Bucharest, Romania

${ }^{3}$ Emergency Universitary Central Military Hospital, Academy of Romanian Scientists, Bucharest, Romania

${ }^{4}$ Emergency Clinical Hospital „St. Pantelimon“, Bucharest, Romania

${ }^{5}$ Clinical Emergency Hospital of Bucharest, Bucharest, Romania

Received 04 Jan 2019, Accepted 25 Febr 2019

https://doi.org/10.31688/ABMU.2019.54.1.22

\section{Abstract}

Vitiligo is a chronic, asymptomatic, disease that affects the patient from a cosmetic point of view. It is characterized by the appearance of depigmented areas on the skin or mucous membranes. Depending on the morphology of the lesions, vitiligo can be classified into: segmental, non-segmented or mixed. Vitiligo is associated with a range of autoimmune disorders, most commonly autoimmune thyroid diseases, alopecia areata, halo nevi, psoriasis, diabetes, etc. Etiology is not entirely elucidated, autoimmune theory related to specific genetic mutations being the most studied.

Keywords: vitiligo, genetics, vitiligo-associated diseases, genetic susceptibility.

\section{RÉSUMÉ}

Implications génétiques et associations entre le vitiligo et les maladies associées au vitiligo

Le vitiligo est une maladie chronique, asymptomatique, qui affecte le patient du point de vue esthétique. Elle se caractérise par l'apparition de zones dépigmentées sur la peau ou les muqueuses. Selon la morphologie des lésions, le vitiligo peut être classé en : segmentaire, non segmenté ou mixte. Le vitiligo est associé à une gamme de troubles auto-immuns, le plus souvent de maladies thyroïdiennes auto-immunes, d'alopécie en aires, de nævi halo, de psoriasis, de diabète, etc. Létiologie est encore trop peu élucidée, la théorie auto-immune liée à des mutations génétiques spécifiques étant la plus étudiée.

Mots-clés: vitiligo, génétique, maladies associées au vitiligo, susceptibilité génétique. 


\section{INTRODUCTION}

Vitiligo is an acquired depigmentation disorder of the skin of unknown etiology, which is characterized by depigmented areas due to the loss of melanocytes. Prevalence is dependent on ethnicity, gender and age, in Europe being estimated between 0.5\% and $1 \%$ of the population ${ }^{1,2}$. A multicenter survey estimated the prevalence in Mexico at $0.21 \%{ }^{3}$. A metaanalysis has shown a global prevalence of $1.8 \%$, while global distribution tends to Asians and Africans ${ }^{4}$. It may occur at any age, but the onset generally occurs between 10 and 30 years old, affecting both sexes equally $^{5}$. It is an asymptomatic condition, itching may rarely occur and has an increased incidence of sunburn on depigmented areas.

The classification of vitiligo is described in Table 1.

\section{Genetic association between Vitiligo and OTHER CONDITIONS}

The increased incidence of association between vitiligo and other conditions is well-known. The disease, although limited only to the skin, has an increased association with other conditions, such as thyroid disease (hyperthyroidism and hypothyroidism), Addison's disease, alopecia areata, diabetes mellitus, pernicious anemia, systemic lupus erythematosus, rheumatoid arthritis, inflammatory bowel disease, Sjögren's syndrome, dermatomyositis, scleroderma, ocular and auditory abnormalities, psoriasis and atopic dermatitis ${ }^{7-9}$. The quality of life is low in these patients and the incidence of depression is very high. Treatment is not curative, but it aims to improve symptomatology by repigmentation ${ }^{10}$.

The association of vitiligo with other diseases (Table 2) led to the hypothesis that common genetic factors may be involved. The possible genetic predisposition and mutations responsible for the appearance of these diseases must be searched.
Vitiligo is a condition involving complex genetic factors. Studies regarding the genomic association have described about 50 susceptibility loci for vitiligo, $90 \%$ of which confer innate and adaptive immunity, while $10 \%$ confer melanocytic antigens and stress response pathways ${ }^{11}$. Among the genes involved in vitiligo are: non-HLA genes (DDR1, XBP1, NLRP1, PTPN22 and COMT) and HLA genes (HLA-A2, HLA-DR4 and HLA-DR7) ${ }^{12,13}$. Linkage and association studies have also provided strong support for vitiligo susceptibility genes on chromosomes $4 \mathrm{q} 13$ $\mathrm{q} 21,1 \mathrm{p} 31,7 \mathrm{q} 22,8 \mathrm{p} 12$ and $17 \mathrm{p} 13^{14}$.

Glutathione peroxidases (GPX) - their main function is to protect the body against damage caused by free oxygen radicals. There are five forms: GPX1 - cell, GPX2 - gastrointestinal, GPX3 - plasma, GPX4 - phospholipid, and snGPX - sperm. GPX1 is a major intracellular anti-oxidant enzyme, and the Leu200Pro (rs1050450) polymorphism has been reported to be associated with decreased activity in various diseases ${ }^{15}$. For the first time, Mansuri at al confirmed the genetic association of vitiligo with variations in GPX1, which contains at least two independent risk signals, one marked by Arg5Pro SNP and another labeled Leu6Pro ${ }^{16}$.

The analysis of haplotype/gene-gene interaction revealed that SOD2 + 47C / T and GPx1 + 599C / T are involved in the imbalance (D: 0.168; r2: 0.10) and individuals with this combination had a 1.273 higher risk [OR; CI (95\%)] to develop type II diabetes mellitus ${ }^{17}$. GPX1 deficiency has also been implicated in the promotion of endothelial dysfunction, heart failure and abnormal structural changes in vasculature and myocardium ${ }^{18}$. GPX1 seems to be associated with alopecia areata, coronary heart disease, Addison's disease, psoriasis ${ }^{1921}$.

Catechol-O-methyltransferase (COMT) gene inactivates dopamine, epinephrine and norepinephrine in the nervous system. COMT gene located on the 22q11.1-q11.2 locus, due to its involvement in

Table 1. Vitiligo classification ${ }^{6}$.

\begin{tabular}{|c|c|}
\hline The type of vitiligo & Subtype - explanation \\
\hline Vitiligo non-segmental & $\begin{array}{l}\text { Acrofacial - usually limited to face, head, hands and feet. } \\
\text { Generalized - symmetrical macules on hands, fingers, face and trauma areas } \\
\text { Mucosal - involves oral and / or genital mucosa, but also involves other areas } \\
\text { Universal - depigmentation occurs on } 80-90 \% \text { of body surface area }\end{array}$ \\
\hline Vitiligo segmental & $\begin{array}{l}\text { Unisegmental - one or more macules on one side of the body } \\
\text { Bisegmental - two segmental injuries distributed unilaterally or bilaterally } \\
\text { Plurisegmental - multiple lesions distributed unilaterally or bilaterally }\end{array}$ \\
\hline Mixed vitiligo & $\begin{array}{l}\text { The combination of segmental vitiligo with non-segmental - segmental vitiligo followed by } \\
\text { non-segmental vitiligo at least } 6 \text { months difference }\end{array}$ \\
\hline Vitiligo unclassified & $\begin{array}{l}\text { Focal - isolated macules that do not have a segmental distribution, do not evolve in non-seg- } \\
\text { mental vitiligo for at least two years } \\
\text { Mucosal - involves only oral or genital mucosa }\end{array}$ \\
\hline
\end{tabular}


Table 2. Possible genetic associations between vitiligo and other diseases.

$\begin{array}{cc}\begin{array}{c}\text { Gene associated with } \\ \text { vitiligo }\end{array} & \text { Other associated conditions } \\ \text { Type II diabetes mellitus } \\ \text { Alopecia areata } \\ \text { Coronary heart disease } \\ \text { Addison's disease } \\ \text { Psoriasis }\end{array}$

the catecholamine metabolism, was linked to the increase in oxidative stress in vitiligo ${ }^{22}$.

The COMT gene has also been associated with schizophrenia, bipolar disorder and the polymorphisms implicated in schizophrenia; also, the COMT polymorphism contributes significantly to the development of late-onset alcoholism ${ }^{23,24}$. COMT has been found in the skin of patients with psoriasis; Catechol-O-methyltransferase (COMT) 158 polymorphism can reduce the activity of the COMT enzyme, that may trigger defective differentiation of keratinocytes in psoriasis ${ }^{25}$.

Discoidin domain receptors (DDRs) are a novel class of receptor tyrosine kinases that bind to several collagens and stimulate matrix metalloproteinase production. These discoidin domain receptors are split into two classes, DDR1 and DDR2. The DDR1 gene, located on the $6 \mathrm{p} 21$ chromosome region, is involved in the adhesion of melanocytes to the basal layer by $\mathrm{CCN} 3$ integrin, mutations in this gene have generated a reduction in melanocytic adhesion in the basal membrane ${ }^{26}$. DDR1 is a susceptibility gene for vitiligo, possibly implicating a defective cell adhesion in vitiligo pathogenesis ${ }^{26}$.

The DDR1 was expressed in $63 \%$ of serous ovarian cancer tissue, whereas it was undetectable in normal ovarian surface epithelium; DDR1 was expressed significantly more frequently in high-grade (79\%) and advanced stage (77\%) tumors, compared to low-grade $(50 \%)$ and early stage (43\%) tumors. DDR1 plays a role in the most fatal skin cancer - malignant melanoma ${ }^{27}$.

Encoding Granzyme B (GZMB) is a protein coding gene that is located at $14 \mathrm{q} 12$ and has 5 exons with a length of $3320 \mathrm{bp}$. In a recent GWAS study by Jin et al, examining European populations, SNP rs8192917 from GZMB was found to be significantly associated with vitiligo ${ }^{28}$. Xu et al conducted a study on 973 vitiligo patients, based on genetic association, to investigate possible GZMB genetic contributions to the susceptibility of vitiligo. The authors concluded that the GZMB gene has an important site for vitiligo in the Han Chinese population and can be useful in determining the genetic risk for vitiligo in this population ${ }^{29}$. Thyroid disease has a common feature with vitiligo in GZMB gene ${ }^{30}$.

The protein tyrosine phosphatase N22 (PTPN22), a gene that regulates activities for both $\mathrm{T}$ cells and B cells, located on the 1p13.3-p13.1 locus, has been studied and demonstrated to be an inherited risk factor for generalized vitiligo. Regarding the rheumatoid arthritis and juvenile rheumatoid arthritis in the UK population, studies have shown an increase in the frequency of the PTPN22* $\mathrm{T}$ allele in the cases (17.8\% in RA; $15 \%$ in JIA) compared with controls (10.3\%), with an OR for the allele of 1.88 for RA and 1.53 for JIA. It is also associated with: type 1 diabetes, Graves' disease, rheumatoid arthritis, juvenile idiopathic arthritis, Addison's disease, psoriasis, inflammatory bowel disease ${ }^{31,32}$.

Nuclear localization leucine-rich-repeat protein 1 (NLRP1) gene is a key regulator of the innate immune system, it is located on the chromosome $17 \mathrm{p} 13$ region and has been associated with the risk of generalized vitiligo, but also with several autoimmune diseases associated with vitiligo ${ }^{33}$. NLRP1 was associated with the following diseases: type 1 diabetes, Addison's disease, celiac disease, systemic sclerosis, inflammatory bowel disease, thyroid disease ${ }^{34,35}$.

$\mathrm{X}$-box-binding protein 1 (XBP1) gene is a transcription factor located on the 22q12 locus, is involved in the expression of MHC class II genes. There has been an increase in XBP1 expression in the skin of the carriers of a particular XBP1. Concerning genetic influence on early onset, early onset of vitiligo is specifically associated with MHC class II indel rs145954018, which contributes substantially to 
the difference in heritability between early onset and late onset subgroups ${ }^{36}$. It has been associated with Crohn's disease ${ }^{37}$.

The vitamin $\mathrm{D}$ receptor (VDR) gene is located on chromosome 12q12-q14. VDR Apal polymorphism increased the risk of vitiligo susceptibility and there is a positive correlation between serum 25 $(\mathrm{OH}) \mathrm{D}$ deficiency and the incidence of vitiligo ${ }^{38,39}$. In this regard, the VDR Apal, BsmI, Fokl gene has been found to be associated with insulin resistance, especially in Caucasians and Asians with dark skin pigmentation ${ }^{40}$. Other research has shown that molecular variants of the VDR gene may be related to the development of colon cancer and influences the susceptibility to age-related changes in cognitive function and depressive symptoms $\mathrm{s}^{41,42}$.

\section{Conclusions}

A variety of genes are involved in vitiligo, not all of the genetic background being completely elucidated yet. The association of vitiligo with other diseases is known, common genetic factors being involved. More studies are needed on the genetic association between vitiligo and vitiligo-associated diseases.

\section{Compliance with Ethics Requirements:}

„The authors declare no conflict of interest regarding this article"

\section{References}

1. Taieb A, Alomar A, Böhm M, et al. The writing group of the Vitiligo European Task Force (VETF) in cooperation with the European Academy of Dermatology and Venereology (EADV) and the Union Européenne des Médecins Spécialistes (UEMS). Guidelines for the management of vitiligo: The European Dermatology Forum consensus. $\mathrm{Br}$ J Dermatol 2013;168(1):5-19.

2. Alikhan A, Felsten LM, Daly M, et al. Vitiligo: a comprehensive overview Part I. Introduction, epidemiology, quality of life, diagnosis, differential diagnosis, associations, histopathology, etiology, and work-up. J Am Acad Dermatol 2011;65(3):473-491.

3. Castañón ER, Torres Bibiano TB, Hernández AH, et al Epidemiologia cutanea en dos sectores de atencion medica en Guerrero, Mexico. Dermatologia; Revista Mexicana 1992;36(1):29-34.

4. Zhang Y, Cai Y, Shi M, et al. The prevalence of vitiligo: A meta-analysis. PLoS One 2016;11(9):e0163806.

5. Halder RM, Taliaferro SJ. „Vitiligo,“ in Fitzpatrick's Dermatology in General Medicine, McGraw-Hill, New York, NY, USA, $7^{\text {th }}$ edition, 2008, p. 616.

6. Ezzedine K, Lim HW, Suzuki T, et al. Revised classification/nomenclature of vitiligo and related issues: the Vitiligo Global Issues Consensus Conference. Pigment Cell Melanoma Res 2012;25(3):E1-13.
7. Iftimie G, Bratu OG, Socea B, et al. Pulmonary involvement in rheumatoid arthritis - another face of the coin. Arch Balk Med Union. 2018;53(1):89-95.

8. Stanescu AMA, Matei A, Grajdeanu IV, at al. The multifactorial approach in the management of psoriasis and its associated comorbidities. Practica Medicala. 2016;11(1):49-52.

9. Paraschiv B, Dediu G, Iancu A, Bratu O, Diaconu C. Superior vena cava syndrome. Arch Balk Med Union 2017;52(1):39-43.

10. Ezzedine, K, Eleftheriadou, V, Whitton, M, et al. Vitiligo. Lancet. 2015; 386(9988):74-84.

11. Jin Y, Birlea SA, Fain PR, et al. Genome-wide analysis identifies a quantitative trait locus in the MHC class II region associated with generalized vitiligo age of onset. J Investig Dermatol. 2011;131(6):1308-1312.

12. Buc M, Fazekasová H, Cechová E, et al. Occurrence rates of HLA-DRB1, HLA-DQB1, and HLA-DPB1 alleles in patients suffering from vitiligo. Eur J Dermatol. 1998;8:13-15.

13. Singh A, Sharma P, Kar HK, et al. HLA alleles and amino-acid signatures of the peptide-binding pockets of HLA molecules in vitiligo. J Invest Dermatol .2012;132(1):124-134.

14. Zhang XJ, Chen J, Liu JB. The genetic concept of vitiligo. Journal of Dermatological Science. 2005;39(3):137-146.

15. Shajil EM, Laddha NC, Chatterjee S, et al. Pigment Cell Res. 2007;20:405-407.

16. Mansuri MS, Laddha NC, Dwivedi M, et al., Genetic variations (Arg5Pro and Leu6Pro) modulate the structure and activity of GPX1 and genetic risk for vitiligo. Exp Dermatol. 2016;25(8):654-657.

17. Vats P, Sagar N, Singh TP, et al. Association of Superoxide dismutase (SOD1 and SOD2) and Glutathione peroxidase 1 (GPx1) gene polymorphisms with Type 2 diabetes mellitus. Free Radical Research. 2015;49(1):17-24.

18. Diaconu CC, Stanescu AMA, Stoian AP, et al. Hyperkalemia and cardiovascular diseases: new molecules for the treatment. Rev Chim (Bucharest). 2018;69(6):1367-1370.

19. Kalkan G, Seçkin HY, Benli İ, et al. Relationship between manganese superoxide dismutase (MnSODAla-9Val) and glutathione peroxidase (GPx1 Pro 197 Leu) gene polymorphisms and alopecia areata. Int J Clin Exp Med. 2015;8(11):21533-40.

20. Manea M, Marcu D, Stoian AP, et al. Heart failure with preserved ejection fraction and atrial fibrillation. Rev Chim (Bucharest). 2018;69(11):4180-4184.

21. Roucher-Boulez F, Mallet-Motak D, Tardy-Guidollet V, et al. News about the genetics of congenital primary adrenal insufficiency. Annales d'Endocrinologie. 2018;79(3):174-181.

22. Türsen U, Kaya TI, Erdal ME, et al. Association between catechol. O-methyltransferase polymorphism and vitiligo. Arch Dermatol Res. 2002;294:143-146.

23. Shifman S, Bronstein M, Sternfeld M, et al. COMT: A common susceptibility gene in bipolar disorder and schizophrenia. Am J Med Genet. 2004;128B:61-64.

24. Tiihonen J, Hallikainen T, Lachman H, et al. Association between the functional variant of the catechol-O-methyltransferase (COMT) gene and type 1 alcoholism. Molecular Psychiatry 1999;4:286-289.

25. Stanescu AMA, Diaconu CC, Iancu MA, et al. Psoriasis and cardiovascular diseases: current developments in medical research. Revista Medicala Romana 2018;LXV(1):41-44.

26. Silva de Castro CC, do Nascimento LM, Walker G, et al. Genetic variants of the DDR1 gene are associated with vitiligo in two independent Brazilian population samples. J Invest Dermatol 2010;130(7):1813-1818. 
27. Quan J, Yahata T, Adachi S, et al. Identification of receptor tyrosine kinase, Discoidin Domain Receptor 1 (DDR1), as a potential biomarker for serous ovarian cancer Int J Mol Sci 2011;12(2):971-982.

28. Jin Y, Andersen G, Yorgov V, et al. Genome-wide association studies of autoimmune vitiligo identify 23 new risk loci and highlight key pathways and regulatory variants. Nature genetics. 2016;48(11):1418-1424.

29. Xu M, Liu Y, Liu Y, et al. Genetic polymorphisms of GZMB and vitiligo: A genetic association study based on Chinese Han population. Scientific reports. 2018;8(1):1-5.

30. Spritz RA. Six decades of vitiligo genetics: genome-wide studies provide insights into autoimmune pathogenesis. Journal of Investigative Dermatology. 2012;132(2):268-273.

31. Hinks A, Barton A, John S, et al. Association between the PTPN22 gene and rheumatoid arthritis and juvenile idiopathic arthritis in a UK population: Further support that PTPN22 is an autoimmunity gene. Arthritis $\mathbb{E}$ Rheumatism. 2005:52:1694-1699.

32. Anghel R, Iorga L, Marcu D. The role of Bosniak classification in the assessment of renal cystic masses and in the therapeutical protocol. Arch Balk Med Union. 2018;53(3):445-448.

33. Jin Y, Mailloux CM, Gowan K, et al. NALP1 in vitiligo-associated multiple autoimmune disease. N Engl J Med. 2007;356(12):1216-1225.

34. Magitta NF, Bøe Wolff AS, Johansson S, et al. A coding polymorphism in NALP1 confers risk for autoimmune
Addison's disease and type 1 diabetes. Genes Immun. 2009;10(2):120-124.

35. Diaconu CC, Dragoi CM, Bratu OG, et al. New approaches and perspectives for the pharmacological treatment of arterial hypertension. Farmacia. 2018;66(3):408-415.

36. Jin, Y, Roberts, G, Ferrara, T M, et al. Early-onset autoimmune vitiligo associated with an enhancer variant haplotype that upregulates class II HLA expression. Nature communications. 2019;10(1): 391.

37. Kaser A, Lee AH, Franke A, et al. XBP1 links ER stress to intestinal inflammation and confers genetic risk for human inflammatory bowel disease. Cell. 2008;134(5):743-756.

38. Zhang JZ, Wang M, Ding Y, et al. Vitamin D receptor gene polymorphism, serum 25-hydroxyvitamin D levels, and risk of vitiligo: A meta-analysis. Medicine. 2018; 97(29): e11506.

39. Stanescu AMA, Grajdeanu IV, Iancu MA, et al. Correlation of oral vitamin $\mathrm{D}$ administration with the severity of psoriasis and the presence of metabolic syndrome. Rev Chim (Bucharest). 2018;69(7):1668-1672.

40. Han F, Lv Y, Gong L, et al. VDR Gene variation and insulin resistance related diseases. Lipids in Health and Disease. 2017;16(1):157.

41. Diaconescu D, Pantea Stoian A, Socea LI, et al. Hepatorenal syndrome: a review. Arch Balk Med Union. 2018;53(2):239-245.

42. Kuningas M, Mooijaart SP, Jolles J, et al. VDR gene variants associate with cognitive function and depressive symptoms in old age. Neurobiology of Aging. 2009;30(3):466-473. 